\title{
Economic and social development based on education, research and industry
}

\author{
Constantin Anghelache $e^{1,2}$, Mădălina-Gabriela Anghel ${ }^{2}$, and Ștefan Virgil Iacob ${ }^{2 *}$ \\ ${ }^{1}$ Bucharest University of Economic Studies, Department of Statistics and Econometrics, 15-17 \\ Calea Dorobanti, Bucharest, Romania \\ ${ }^{2}$ Artifex University of Bucharest, Department of Finance and Accounting, 47 Economu Cezarescu \\ Street, Bucharest, Romania
}

\begin{abstract}
The economic and social evolution in the current context, of the sanitary and economic-financial crisis raises problems regarding the future economic evolution. The authors highlight the current situation of the Romanian economy. Measures must be taken to ensure that standards in education and research are raised. The industry needs to modernize on digitalization, robotics and other achievements of science. Today, the industry needs to develop based on the latest achievements of science. Innovation must be the basis of high-quality education, be an element of research, and research without innovation cannot exist. The method used is that of comparative study, static and dynamic, and the use of statisticaleconomic models to highlight the role of education, research and industry, based on innovation. From the data we have at our disposal, it results the need for these aspects to constitute the equilateral triangle of a program of economic and social development in the future. The final conclusion of this research is the need to intensify efforts, including financing an economy based on deep and quality education, connecting high-level education with research and bringing through innovations new attributes that the industry must fulfil.
\end{abstract}

\section{Introduction}

The issue of a country's economic growth and socio-economic development is a topical issue both in the European Union and in the member countries. Of course, social capital, labour and resources must be used as efficiently as possible so as to achieve the most obvious economic growth possible.

Research in all fields, but especially in industry is an important element on which depends the economic evolution of a country, through the participation of this branch in the growth of Gross Domestic Product.

The period that humanity is currently going through, that of the pandemic and economic-financial crisis is important. Therefore, in rehabilitation and resilience programs, countries should consider allocating additional amounts to maintain and improve the quality of education and especially its focus on practical work.

\footnotetext{
* Corresponding author: stefaniacob79@yahoo.com
} 
The field of research must be specific to each field of activity and even more so to industry, which in the current conditions of digitization, robotization and the introduction of modern methods is the only one able to ensure the restructuring of industry and the economy in general, on new bases achievements in science, technology and innovation.

Research is a field without which evolution in any field of activity cannot be achieved in terms of orientation, control and direction of evolution. In this context, there are sufficient research programs in the European Union to which all countries of the world have joined or are joining. We talked about the recovery strategy and resilience, which is a particularly important stage in the current conditions, in which due to the economicfinancial crisis combined and influenced by the pandemic crisis led to modest results, which must be invigorated. We do not address the issue of lei as a whole in this article, but with an emphasis on the need to increase research and raise it to higher levels of economic intelligence.

In this direction, the amounts allocated by each state to increase new opportunities for recovery and transformation of the economy of the future must be an important element. Unfortunately in Romania, in this context where there are these concerns, we find that research is allocated $0.48 \%$ of Gross Domestic Product, a tiny amount that cannot result in outstanding results in terms of innovation, discovery of new directions and bringing the economy to a higher level. This triumvirate of education, research, industry should be an equilateral triangle, in which the three areas should be given increased attention, so that education is a high level, especially in technical and economic fields, research should absorb from education in this field those positive elements, which can influence through inventions and innovations economic growth. Also, the industry as the main beneficiary of a high class education and a high quality research, can structure a series of fields, subdomains, towards what is supposed to be the economy of the future. The industry can develop without a doubt and maybe based on the process of digitization, robotization, introduction of nanotechnologies and many other methods.

In this article we have invented one by one the three aspects and presented some data on Romania and how it has acted and is acting in the direction of increasing the quality of education, research and consequently the development of industry and economic growth at the expense of this source of each country. At the moment we can no longer talk about reindustrialization, which is an already obsolete term, but about the development and putting the industry on new qualitative bases, leading to the increase of economic results.

\section{Literature review}

Akçomaka and ter Weel [1] studied the correlation between innovation and economic growth. Anghelache, Petre and Olteanu [2] presented a series of models used in macroeconomic analysis. Anghelache, Anghel and Dumbravă [3] highlighted that there is a large discrepancy between European states in terms of funding for research and innovation, being an important element in seeking a wider cooperation within the European Union. Arribas, Perez and Tortosa-Ausina [4] considered that measuring globalization requires a standard of international integration, proposing and using a set of indicators, for each specific economy and for the world economy. Cincera and Veugelers [5] analysed the gap in the European Union regarding research and development. Cruz-Jesus, Oliveira and Bacao [6] presented elements on the digital divide in the EU. Fischer [7] studied the correlation between different regions and technological growth in Europe. Halász and Michel [8] addressed a number of issues related to educational policies. Marozau, Guerrero and Urbano [9] highlighted the importance of higher education institutions in different stages of economic development. Rodríguez-Pose [10] referred to the determinants of innovation in regional areas in Europe. Saarinen and Ursin [11] 
assessed the impact of policy change on higher education. Schlicht, Stadelmann-Steffen and Freitag [12] analysed inequality in the European Union's education systems.

\section{Methodology, data, results and discussions}

In 2015, the European Commission set the main priorities in front of the member countries, thus mentioning a series of priorities that are of particular importance in the individual evolution of the member countries of the European Union but also as a whole. Of the priorities set, three are particularly important in adjusting Member States' national economies, in trying to bring economic and social conditions closer together and with a view to supporting Eastern European countries that have had some difficulty in aligning with European standards and trends. Therefore, the creation of the objectives concerned job creation, investment-based growth and the resettlement of the internal market in the European Union. All this can only be achieved by allocating more substantial amounts to research in all fields, but especially in the field of industry, which is an important element on which the economic evolution of a nation depends.

With regard to education, it must be viewed equally and equitably, without discrimination, and be a civic component for the whole population. Also, open and innovative education as well as training must include the elements that the digital age offers. In the same vein, teachers must be a strong support in the preparation and education of generations, because education, as well as further training, must be transparent and based on the qualities of individuals, but also be oriented towards the mobility they have requires labour in each country's economy. Government measures must ensure the improvement of the quality of teachers, the teaching factor, the development of those qualities that guarantee the symbiosis between the teacher and the staff in training and last but not least, to guarantee a high level, at the international standard, on which demands international education. The Bologna Program provides for training on the basis of transferable credits, which ensures, in all circumstances, the possibility of further development of education, invention and innovation.

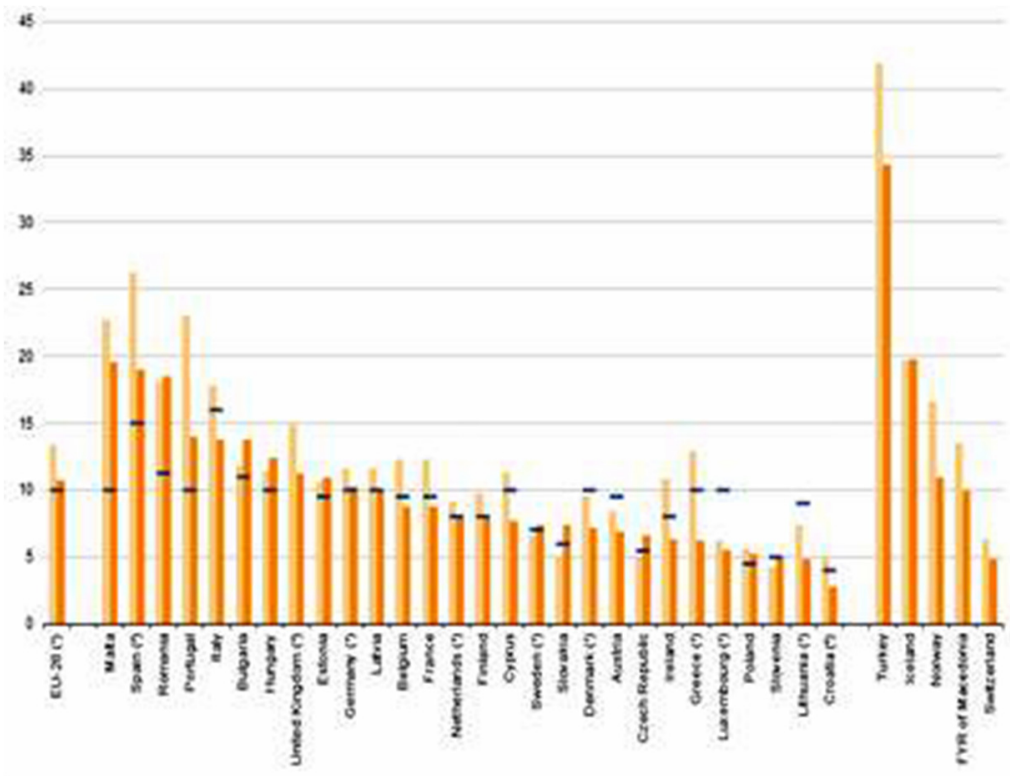

Fig. 1. Evolution of the number of dropouts, in education and training, 2014 and 2019 (\% of the population aged 18-24). Source: Eurostat (Data processed by authors). 
Internationally, the requirements expressed by the United Nations Educational, Scientific and Cultural Organizations within UNESCO and the United Nations Institute of Statistics must be taken into account and the OECD provisions on standards contained in Eurostat documents, the Statistical Office of the United Nations European Union.

An interesting problem that has developed and that takes into account the correlation between the supply of jobs after graduation, for those who finish their courses and then the material situation, which allows them or not to finish their courses, depends on the difficulties of the labour market. Thus, Figure 1 is presented the evolution of the number of dropouts, in education and training, the years 2014 and 2019 (\% of the population aged 18-24).

The distribution of those who drop out of education before graduation, between 18 and 24 years, shows us how many of them enter the field of work, how many do not enter the field of work, how many of them are men and would like to work and how many of them are who would not want to work. In the case of Romania, the total number of those who drop out of school and are engaged in activity or not, is 19,100 annually, of which 9,350 falls into the field of work and 9,750 do not fall into the field of work. Of these, $4.4 \%$ are those who do not fit and would like to find a job, and $5.3 \%$ would not. It is a situation that is particular to each country and that also depends on the education system, on the incentives that those who are called to take and finish their courses see in terms of their future.

In the same vein, any specialist who has completed a complex training, aged between 25 and 64, must aim to pursue a long-term training. This can be done through specialization courses, through professional reconversion, by following particular forms in the field of research, application, innovation. Thus, in 2019, the proportion of people aged between 25 and 64 in the European Union, who participated in further training and education was $10 \%$. There is also an appreciation and analysis from the point of view of people who complete their training at an older age, all depending on the requirements of the labour market, the incentives that those who see and use as training, improvement to acquire a position better social.

When it comes to spending on education, it must be a priority for each country. Also, health and education are the two elements of the physical and intellectual health of a country's population, and the issue of education allowances is related to the level of development of that country, the national education system, the labour market supply and, last but not least, the labour market the size of the Gross Domestic Product, which is a key element in the allocation of funds for national expenditure. In most Member States of the European Union, education expenditure is borne by the government, but recently the private education system has developed, which has complemented the public expenditure made by the Member States on education. Public spending on education was 672 billion higher in 2014 than a decade ago. There are countries where the level of education

allowances was $5.3 \%$ of Gross Domestic Product. This group includes countries such as Greece and Croatia, and the highest level of government allocations for education are in Denmark with $8.8 \%$ of GDP, Malta, Cyprus, Belgium, where the level of allocations was between 3.1 and $6.5 \%$ of GDP, but also countries like Lithuania, Romania, Latvia, which were well below this level of allocations in the national budget expressed as a percentage of Gross Domestic Product to have a benchmark. The processed data were represented in Figure 2. 


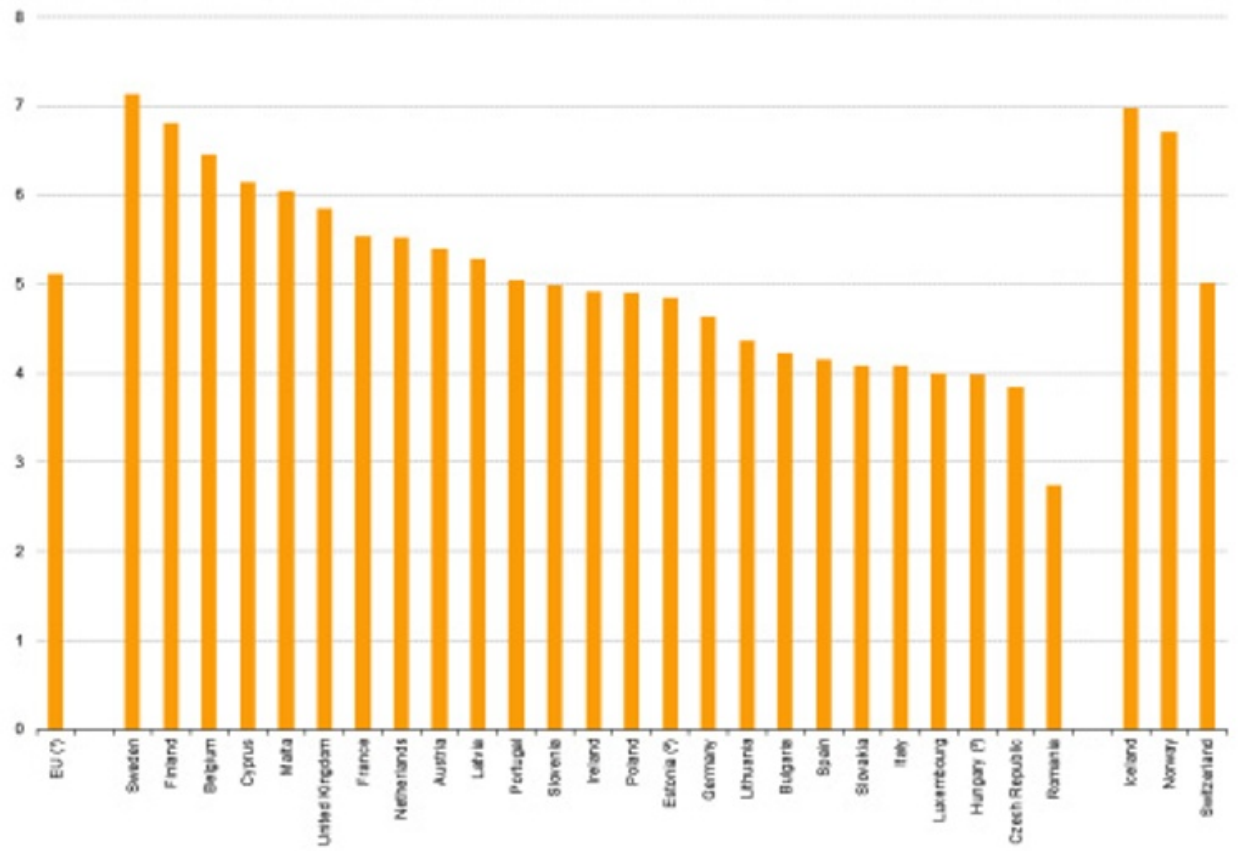

Fig. 2. Public expenditure on education as a share of GDP, 2019 (\%). Source: Eurostat (Data processed by authors).

The European Union's strategy for promoting entrepreneurial success aims to improve the business environment for small and medium-sized enterprises, which must make an increasing contribution to the global potential of economic development. Thus, the European Union's strategy until 2020 on the program to increase the competitiveness of small and medium-sized enterprises was based on a budget of about 2.4 billion euros. The allocation of these impressive sums has been aimed at improving access to finance, access to the European Union market, supporting entrepreneurs and improving the conditions for competitiveness for small and medium-sized enterprises. Over time, a number of proposals have been made to increase the potential of small and medium-sized enterprises, remove remaining barriers and, above all, transform and ensure a quality entrepreneurial culture in the European Union. The European Union's strategy in this area also focused on improving the quality of entrepreneurship for both men and women, creating a management-based environment according to requirements, access to the Community market and increasing the conditions for attracting investors to activities for all European Union countries.

By studying the statistical data published by Eurostat we can ensure and find answers to questions related to the structure of the business environment in the European Union, with emphasis on highlighting the level of gross value added, investment, access to the labour market, in the most diverse activities.

This analysis takes into account the fact that in the field of industry and services countries have specialized, in their own way, in certain activities that need to become complementary and ensure wider cooperation within the European Union. The essential element in terms of the development of industry and services is the increase in productivity and profitability, so as to ensure the increase of concrete results highlighted by the most synthetic indicator of results, the Gross Domestic Product.

In Romania, the monthly evolution of industrial production, by total industry, extractive industry, manufacturing industry and energy, in the period January 2015 November 2020 is outlined in Figure 3. 


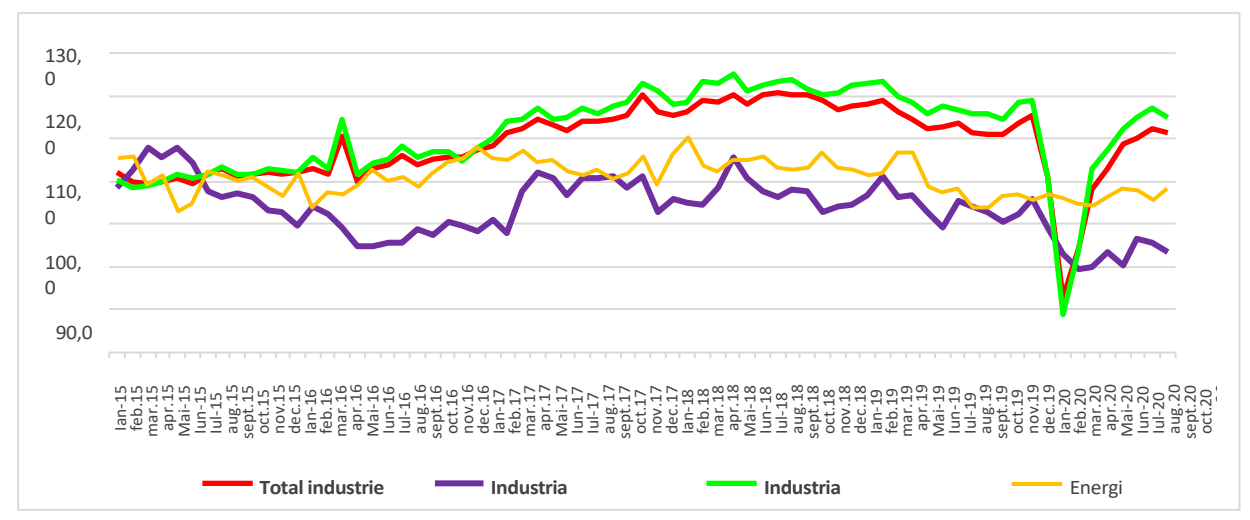

Fig. 3. Monthly evolution of industrial production, January 2015 - November $2020(2015=100)$.

In Romania, the industrial production decreased in November 2020 compared to the previous month by $4.8 \%$ as gross series and by $0.6 \%$ as series adjusted according to the number of working days and seasonality. Also, industrial production decreased compared to the corresponding month of the previous year by $3.4 \%$ as gross series, but increased by $0.4 \%$ as series adjusted according to the number of working days and seasonality. At the same time, in the first eleven months of 2020, respectively the period 01.01 - 30.11.2020, compared to the period $01.01-30.11 .2019$, the industrial production was lower by $10.2 \%$ as gross series and by $10.5 \%$ as series adjusted according to the number of working days and seasonality.

It is important that, in the light of the results recorded and presented in this research, in terms of education, research and industry, the necessary measures be taken for economic recovery, measures to allocate additional amounts to these key areas. Also, the industry must have the additional financial resources to follow the growth through investments, in order to be able to create new jobs and in this way Romania to be able to align with the requirements of the European market, of the European Union or even more broadly world.

\section{Conclusions}

From this article based on a deep research of education, research and industry in Romania, the authors finally concluded a series of aspects, especially theoretical and somewhat practical. A first conclusion is that without the substantiation and development of a high quality education, combining education with research and the two together with the requirements of the industry to develop on the basis of new, no great progress can be achieved.

Funding for education and research is an aspect that must be taken into account in the sense that without allocating serious sources in the field of funding, research projects cannot be initiated, they cannot be carried out and developed, in the sense of discovering new and new methods applicable in industry, so that the level of production in this branch increases and consequently the concrete results measured by the Gross Domestic Product also increase.

Another conclusion is that researchers must come from specialized higher education institutions, be allocated and be able to be widely applicable to industry. Of course, a forecast in this field can be made using statistical-econometric methods, based on the possibility of obtaining parameters based on which to base the evolutionary directions of 
education and research.

At the same time, the achievement of results in the field of innovation and innovation can be achieved by collaborating researchers with other specialists at European level, starting from the fact that the European Union has established such a directive, to be used in the field of research and industry evolution. Of course, this is only part of the projects that the European Union is considering, in the sense of attracting as many states as possible to major projects that will materialize with results in the field of innovation and invention, which then applied in the economic process to bring desired results.

\section{References}

1. I.S. Akçomaka, B. ter Weel, Social capital, innovation and growth: Evidence from Europe. Eur Ec Rev, 53 (5), 544-567 (2009)

2. C. Anghelache, A. Petre, C. Olteanu, Some concepts and econometric models of macroeconomic performance analysis, Rom Statist Rev, Supplem, 4, 12-20 (2019)

3. C. Anghelache, M.G. Anghel, G.Ș. Dumbravă ,The role of science, technology and innovation in the evolution of the member states of the European Union. The 9th International Conference of Management and Industrial Engineering "Management Perspectives in the Digital Transformation", November 14th - 16th, 2019, University Politehnica of Bucharest, 57-67, (2019)

4. I. Arribas, F. Perez, E. Tortosa-Ausina, Measuring Globalization of International Trade: Theory and Evidence. World Develop, 37(1), 127-145 (2009)

5. M. Cincera, R. Veugelers, Young leading innovators and the EU's R\&D intensity gap. Econ of Innov and New Tech, 22(2), 177-198 (2013)

6. F. Cruz-Jesus, T. Oliveira, F. Bacao, Digital divide across the European Union. Inform \& Manag, 49(6), 278-291 (2012)

7. M. Fischer, Regions, Technological Interdependence and Growth in Europe, Rom Journ of Region Science, 3(2), 1-17 (2009)

8. G. Halász, A. Michel, Key Competences in Europe: interpretation, policy formulation and implementation. Eur Journ of Educat, 46(3), 289-306 (2011)

9. R. Marozau, M. Guerrero, D.J. Urbano, Impacts of Universities in Different Stages of Economic Development. Journ of the Knowledge Econ, 1-21(2016)

10. A. Rodríguez-Pose, Research and Development, Spillovers, Innovation Systems, and the Genesis of Regional Growth in Europe. Region Stud, 42(1), 51-67 (2008)

11. T. Saarinen, J. Ursin, Dominant and emerging approaches in the study of higher education policy change. Stud in Higher Educat, 37(2), 143-156 (2011)

12. R., Schlicht, I. Stadelmann-Steffen, M. Freitag, Educational Inequality in the EU: the Effectiveness of the National Education Policy. Eur Union Pol, 11(1), 29-59 (2010) 